\title{
Who I am asking about: What the sentence endings imply about the unexpressed subjects in wh-questions
}

\author{
Katsunobu Izutsu \\ HOKKAIDO UNIVERSITY OF EDUCATION \\ idutsu@gmail.com \\ Yong-Taek Kim \\ GEORGIA INSTITUTE OF TECHNOLOGY \\ muchak@gmail.com
}

\begin{abstract}
This study demonstrates that the sentence endings of Korean and Japanese $w h$-questions can be analyzed as serving to evoke and, in a weaker sense, to mark an unexpressed verb subject. This study further contends that the endings are not complex forms with successive morphemes each contributing to the whole meaning but rather simplex forms each of which has its own meaning and function. This study argues that pragmatic groupings of event participants help the sentence endings to mark subjects in the Korean and Japanese languages as well as other languages of the world.
\end{abstract}

\section{Introduction}

This study advances the idea that the sentence endings used in Korean and Japanese wh-questions can be viewed as marking the unexpressed subjects of the verbs in the sentences. The Korean and Japanese languages have a rich variety of sentence endings or sentence-final expressions (Sohn 1999; Kim 2001; Nitta 1999). For example, the conversation in (1) below shows that sentence endings such as -ssna, -ssdeora, -ssji, -ngeoya, -sseulgga, -ngeolgga, -ngeoji, and -sseo can occur in the parenthesized 
position of Korean example (1a), and sentence-final expressions like -taroo, -tadaroo, -takana, -ta, -takke, -tandatta, -tandakke, -tandaroo, tandarooka, -tanokana, and -tano can occur in the position of Japanese example (1b). ${ }^{1}$
(1) a.
Jinanbeon-e eonje Cheolsu-reul
manna-(
) ?
last:time-DAT when Chulsu-ACC
meet-PST.SE
'When did I[you/(s)he/we] meet Chulsu last time?'
b. Zenkai itu Yamada-ni at-( )?
last:time when Yamada-DAT meet-PST.SE
‘When did I[you/(s)he/we] meet Yamada last time?' JAPANESE

When the Korean sentence ending -ssna occurs in (1a), the unexpressed subject of the verb manna, 'meet,' can be 1st-person 'I,' 3rd-person '(s)he,' inclusive 'we,' or exclusive 'we.' However, when the endings -ssdeora and ssji are used, the unexpressed subject can be interpreted as 'I,' 'you,' '(s)he,' or 'we.' When the endings -ngeoya, -sseulgga, -ngeolgga, and -ngeoji are adopted, the unexpressed subject is understood to only mean '(s)he.' When the ending -sseo is employed, the unexpressed subject is interpreted as 'you' or '(s)he.'

Likewise, when the Japanese sentence endings -taroo, -tadaroo, and takana are used, the unexpressed subject of the verb au, 'meet,' can be 'I,' '(s)he,' or 'we.' Meanwhile, when the sentence endings -ta, -takke, tandatta, and -tandakke are employed, the unexpressed subject can be understood to be 'I,' 'you,' '(s)he,' or 'we.' When the endings -tandaroo, tandarooka, and -tanokana are adopted, the unexpressed subject is understood to only mean '(s)he.' When the ending -tano occurs in the sentence, the unexpressed subject is interpreted as 'you' or '(s)he.'

We contend that these endings are not complex forms with successive morphemes each contributing to the whole meaning but rather more or less "prefabricated" (Barlow 2000) simplex forms each of which, as a whole, has its own meaning and function that can largely be treated as unexpressed subject marking in a weaker sense. Such subject marking can be seen as motivated by major types of person grouping reported in crosslinguistic studies such as Cysouw (2000) and Siewierska (2004). We argue that pragmatic groupings of event participants help the sentence endings to mark subjects in Korean and Japanese as well as other languages of the world.

Although neither Korean nor Japanese is ordinarily considered to have anything like subject agreement or marking on verbs (Shibatani 1990: 362) except for honorifics (ibid.: 295, 364), the endings used in $w h$ questions can be viewed as serving to evoke and thus to mark the verb subject in a weaker sense. A comparable weak subject agreement or

\footnotetext{
1 The following abbreviations are used for glossing example sentences: ACC (accusative), DAT (dative), EVD (evidentiality), IP (interjectory particle), NOM (nominative), PST (past tense), SE (sentence ending).
} 
marking is observed in Tibetan languages; in declaratives, one form of copula marks the 1st-person subject and another marks the 2nd/3rdperson subject, whereas in interrogatives, the former form marks the 2ndperson subject, and the latter form marks the 1st/3rd-person subjects (Sun 1993; Tournadre 2008). The 1st/3rd-person grouping and the 2nd/3rdperson grouping found here are seen as based on a pragmatic grouping of "anchoring speakers" (Koguma \& Izutsu 2017). Likewise, the weak subject marking of the Korean and Japanese endings can also be accounted for with respect to different types of pragmatic grouping of participants in speech-event conceptions.

\section{Japanese sentences ending in wh-questions}

Here we will examine the unexpressed subject reference in Japanese $w h$ questions.

\subsection{Japanese past endings in wh-questions}

First, we look at a Japanese wh-question of past-time reference, as illustrated in (2). This is a conversation between $A$ and $B$, in which they are talking about friends of theirs, C ('she') and Yamada ('he'). A tells B that A heard that $\mathrm{C}$ had met Yamada last weekend. $\mathrm{B}$ then asks $\mathrm{A}$ when a certain person met Yamada last time. In Japanese and Korean, it is very common that the verb subject is left unexpressed like this. Most of the earlier studies have taken the position that such an unexpressed verb subject can be appropriately inferred and interpreted in terms of ellipsis and recovery of pronominal elements: e.g., various "empty categories" and "linguistic context" (Shibatani 1990: 362). However, such an explanation cannot provide an adequate account for the abundance of sentence final expressions in otherwise identical sentences like (2).

(2) (A, B, and C are Yamada's friends)

A: C-ne syuumatu Yamada-ni at-ta-ndatte.

$\mathrm{C}$-IP weekend Yamada-DAT meet-PST-EVD

'C says she met Yamada last weekend.'

B: A, soo. Zenkai itu at-taroo/tadaroo/takana?

oh so last:time when meet-SE

'Oh, really? When did (I/she/we) meet him [Yamada] last time?'

Here the sentence-final position of B's second utterance can be occupied by four classes of sentence endings, as shown in table 1 below. Here the numbers, 1 through 3 , indicate 1 st, 2 nd, and 3 rd person, respectively. We adopt the label ' $\mathrm{JP}$ ' to refer to each of the four classes of Japanese past endings. When the sentence endings in class JP1 (-taroo, -tadaroo, and takana), represented in single-underlined letters in the table, are used as in (2), the unexpressed subject of the verb au, 'meet,' can be 'I,' 'she,' or 'we,' as indicated in the translation of B's utterance. 
Table 1: Person reference in Japanese past (JP) sentence endings

\begin{tabular}{|c|c|}
\hline 1 & $\begin{array}{l}\text {-taroo, -tadaroo, -takana (class JP1) } \\
\text { tandakke (class JP2) }\end{array}$ \\
\hline 2 & -ta, -takke, -tandatta, -tandakke (class JP2); -tango (class \\
\hline 3 & 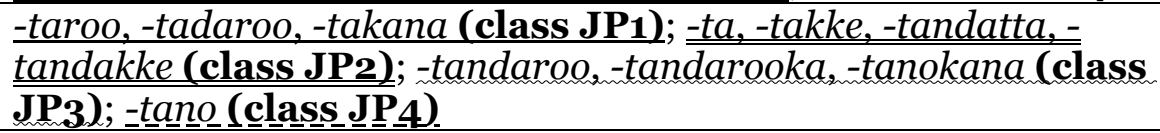 \\
\hline $1+2$ & (class JP1); (class JP2) \\
\hline $1+3$ & (class JP1); (class JP2) \\
\hline $1+2+3$ & (class JP1); (class JP2) \\
\hline $2+3$ & (class JP2); (class JP4) \\
\hline
\end{tabular}

Meanwhile, when the sentence endings in class JP2 (-ta, -takke, -tandatta, and -tandakke) are adopted, represented in double-underlined letters, the unexpressed subject can be understood to be any of the following: 'I,' 'you,' 'she,' or 'we.' Likewise, when the sentence endings in class JP3 (-tandaroo, -tandarooka, and -tanokana) are used, represented in wavy-underlined letters, the unexpressed subject is understood to only mean 'she.' On the other hand, when the sentence ending in class JP4 (-tano) is employed, represented in broken-underlined letters, the unexpressed subject is interpreted as 'you' or 'she.'

The person distributions of the unexpressed subjects observed with each class of sentence endings in Japanese wh-question (2) can be summarized like (3). This implies that those endings can be viewed as serving to evoke the unexpressed verb subject. We can go one step further and say that those endings can be viewed as marking the unexpressed subjects in a weaker sense. Here as well, the numbers, 1 through 3 , stand for the 1st, 2nd, and 3rd person, respectively. Slashes indicate the relation of 'or,' while a parenthesis indicates that the parenthesized person is optional.

(3) The endings in class JP1 mark $1(+2)(+3) / 3$-person subjects.

[I/we/she'] (Grouping 1)

The endings in class JP2 mark $1(+2)(+3) / 2(+3) / 3$-person subjects. [no exclusion] (Grouping 2)

The endings in class JP3 mark 3-person subjects.

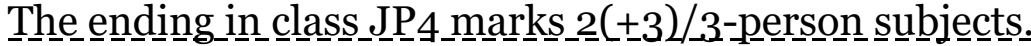
[exclusion of ' you/I'] (Grouping 3) [exclusion_of 'I'] (Grouping_4)

The endings in class JP1 mark unexpressed subjects that correspond to 1st-person 'I' and 3rd person 'she,' but not 2nd person 'you.' They can also mark a combination of 1st person plus 2nd person, or 1st person plus 2nd person plus 3rd person, in which both combinations can be regarded as socalled inclusive 'we.' The JP1 endings can also mark a combination of 1st person and 3rd person, which corresponds to the so-called exclusive 'we.' These combinations along with the 1st-person and the 3rd person constitute one person grouping. Hereafter, we will refer to this person 
grouping as $\mathrm{G}$ 1, for Grouping 1, and represent it in single-underlined letters below as well.

The endings in class JP2 can mark any kind of unexpressed subjects: 2nd-person 'you' in addition to 1st-person 'I,' 3rd-person 'she,' inclusive 'we,' and exclusive 'we.' They do not exclude any person from the possibility of an unexpressed subject. We will refer to this person grouping as G2, for Grouping 2, and represent it in double-underlined letters in the discussion below as well. On the other hand, the $\mathrm{JP}_{3}$ endings mark 3 rdperson subjects only. In other words, they exclude 1st- and 2nd-person subjects. This grouping of 3rd person only will be referred to as $\mathrm{G}_{3}$, for Grouping 3, and represented in wavy-underlined letters. Finally, the JP4 ending marks 2nd- or 3rd-person unexpressed subjects. They can be characterized as excluding the 1st person. We will refer to this fourth person grouping of speaker exclusion as $\mathrm{G}_{4}$, for Grouping 4, and represent it in broken-underlined letters.

\subsection{Japanese non-past endings in wh-questions}

Next, the Japanese $w h$-question of non-past time reference will be analyzed, as instantiated in (4). This is also a conversation between A and $B$, in which they are talking about friends of theirs, C ('she') and Yamada ('he'). In example (4), however, the second utterance of B's is in the nonpast form, as suggested by its translation: "When will (I or she \& I) meet Yamada next time?"

(4) (A, B, and C are Yamada's friends)

A: C-ne syuumatu Yamada-ni at-ta-ndatte.

C-IP weekend Yamada-DAT meet-PST-EVD

'C says she met Yamada last weekend.'

B: A, soo. Kondo itu a-oo/ookana? (class JN1)

oh so last:time when meet-SE

'Oh, really? When will (I/she \& I) meet him [Yamada] next time?'

Here as well four classes of sentence endings can occupy the sentence-final position of B's second utterance, as shown in table 2.

Table 2: Person reference in Japanese non-past (JN) sentence endings

\begin{tabular}{|c|c|}
\hline 1 & $\begin{array}{l}\text {-(y)oo, -(y)ookana (class JN1); -(r)u, -(r)uno, -(r)ukana, - } \\
\text { (r)udaroo, -(r)ukke, -(r)undatta, -(r)undakke (class JN2) }\end{array}$ \\
\hline 2 & $\begin{array}{l}\text {-(r)u, -(r)uno, -(r)ukana, }-(r) \text { udaroo, }-(r) u k k e,-(r) \text { undatta, } \\
\text { (r)undakke (class JN2) }\end{array}$ \\
\hline 3 & 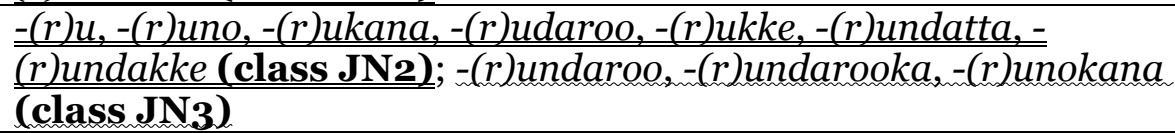 \\
\hline $1+2$ & (class JN2); -(y)ooka (class JN4) \\
\hline $1+3$ & (class JN1); (class JN2) \\
\hline $1+2+3$ & (class JN2); -(y)ooka (class JN4) \\
\hline $2+3$ & (class JN2) \\
\hline
\end{tabular}


We use the label ' $\mathrm{JN}$ ' to refer to the four classes of Japanese non-past endings. When the sentence endings in class $\mathrm{JN} 1$ (-(y)oo and -(y)ookana) are employed, the unexpressed subject of the verb $a u$, 'meet,' must be 'I' or exclusive 'we,' as indicated in the translation of B's utterance. In the meantime, when the sentence endings in class JN2 $(-(r) u,-(r) u n o$, (r)ukana, -(r)udaroo, -(r)ukke, -(r)undatta, and -(r)undakke) are used, represented in double-underlined letters, the unexpressed subject is understood to be any of the following: 'I,' 'you,' 'she,' or 'we.' Similarly, when the sentence endings in class $\mathrm{JN}_{3}$ (-(r)undaroo, -(r)undarooka, and -(r)unokana) are adopted, represented in wavy-underlined letters, the unexpressed subject is understood to be 'she' alone. On the other hand, when the sentence ending in class JN4 (-(y)ooka) is employed, the unexpressed subject cannot mean anything except 'you \& I,' although it can be either 'you \& I' only or 'you \& I \& she.' These are both inclusive 'we,' however.

The person distributions of the unexpressed subjects observed with the four classes of non-past sentence endings in Japanese wh-question (4) can be summed up as shown in (5). The endings in class JN1 mark 1stperson 'I' or exclusive 'we,' namely 'she \& I.' We will refer to this person grouping as $\mathrm{G} 5$ below. In contrast, the endings in class $\mathrm{JN} 2$ can mark any kind of unexpressed subjects: 1st-person 'I,' 2nd-person 'you,' 3rd-person 'she,' inclusive 'we,' and exclusive 'we.' This person grouping is identical with G2, observed with class $\mathrm{JP} 2$ above. They can thus be characterized as no exclusion of any person.

(5) The endings in class JN1 mark 1(+3)-person subjects.

['I' or exclusive 'we'] (Grouping 5)

The endings in class JN2 mark $1(+2)(+3) / 2(+3) / 3$-person subjects.

The endings in class JN3 mark 3-person subjects.

[no exclusion] (Grouping 2)

[exclusion of 'you/I'] (Grouping 3)

The ending in class JN4 marks $1+2(+3)$-person subjects.

[inclusive 'we'] (Grouping 6)

Conversely, the JN3 endings only mark 3rd-person subjects. This is the same as the person grouping found with $\mathrm{JP}_{3}$ seen above. Those endings exclude 1st- and 2nd-person subjects. This grouping of 3 rd person only will be referred to as $\mathrm{G}_{3}$ and represented in wavy-underlined letters. Finally, the JN4 ending marks inclusive 'we' only. The unexpressed subject can either be 'you \& I' or 'you \& I \& she.' This person grouping will be referred to as G6 below.

\section{Korean sentences endings in wh-questions}

Here we will turn to the unexpressed subject reference in Korean whquestions. 


\subsection{Korean past endings in wh-questions}

First, we examine example (6), which is again a conversation between A and B. As in the Japanese example in (2) above, A tells B that A heard that C ('she') had met Chulsu ('him') last weekend. B then asks A when a certain person met Chulsu last time.

(6) (A, B, and C are Chulsu's friends)
A: C-ga jumal-e Cheolsu-reul mana-ss-dae.
C-NOM weekend-at Chulsu-ACC meet-PST-EVD
'(I hear) $\mathrm{C}$ met Chulsu last weekend.'
B: Eo, geurae. Jinanbeon-e eonje jjeum manna-ssna? (class KP1)
oh so last:time-at when about meet-SE
'Oh, really? When did (I/she/we) meet Chulsu last time?'

Here as well, there are four classes of sentence endings that can appear in the sentence-final position of B's second utterance, as shown in Table 3 . When the sentence ending in class KP1 (-ssna) is used, the unexpressed subject of the verb manna, 'meet,' can be 1st-person 'I,' 3rd-person 'she,' inclusive 'we,' or exclusive 'we.' This grouping corresponds to G1, observed with the JP1 endings above, and thus represented in single-underlined letters. Likewise, when the sentence endings in class KP2 (-ssdeora and ssji) are employed, the unexpressed subject can be interpreted as any person of 'I,' 'you,' 'she,' or 'we.' This person grouping is identical to G2, found with $\mathrm{JP2}$, so the KP2 endings are represented in double-underlined letters.

Table 3: Person reference in Korean past (KP) sentence endings

\begin{tabular}{|c|c|}
\hline 1 & -ssna (class KP1); -ssdeora, -ssji (class KP2) \\
\hline 2 & -ssdeora, -ssji (class KP2); -sseo_(class_KP4) \\
\hline 3 & 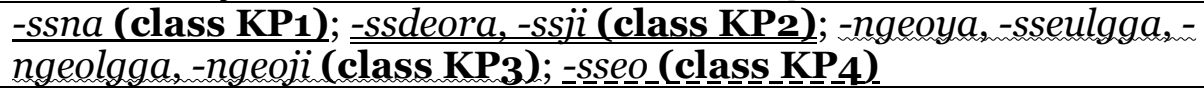 \\
\hline $1+2$ & (class KP1); (class KP2) \\
\hline $1+3$ & (class KP1); (class KP2) \\
\hline $1+2+3$ & (class KP1); (class KP2) \\
\hline $2+3$ & (class KP2); (class KP \\
\hline
\end{tabular}

When the sentence endings in class KP3 (-ngeoya, -sseulgga, -ngeolgga, and -ngeoji) are adopted, the unexpressed subject is understood to only mean 'she.' They are represented in wavy-underlined letters, because their presupposed person grouping conforms with $\mathrm{G}_{3}$, observed with the $\mathrm{JP}_{3}$ endings. When the sentence ending in class $\mathrm{KP} 4$ (-sseo) is used, the unexpressed subject is interpreted as 'you' or 'she.' This person grouping is the same as $\mathrm{G}_{4}$, found with $\mathrm{JP}_{4}$ above, and thus the $\mathrm{KP}_{4}$ endings are represented in broken-underlined letters.

The person distributions of the unexpressed subjects observed with the four classes of past sentence endings in Korean wh-question (6) can be summed up as shown in (7). The ending in class KP1 marks the 
unexpressed subjects of person grouping G1: 1st-person 'I,' 3rd-person 'she,'inclusive 'we,' and exclusive 'we.'

(7) The ending in class KP1 marks $1(+2)(+3) / 3$-person subjects.

[I/we/she'] (Grouping 1)

The endings in class KP2 mark $1(+2)(+3) / 2(+3) / 3$-person subjects.

[no exclusion] (Grouping 2)

The endings in class $\mathrm{KP}_{3}$ mark 3-person subjects.

[exclusion of ' $\left.y o u / I^{\prime}\right]$ (Grouping 3 )

The ending in

[exclussion of ' 'I'](Grouping_-4)

In contrast, the endings in class $\mathrm{KP}_{2}$ mark the unexpressed subjects of person grouping G2, including any of the persons: 1st-person 'I,' 2ndperson 'you,' 3rd-person 'she,' inclusive 'we,' and exclusive 'we.' This involves no person exclusion. Conversely, the $\mathrm{KP}_{3}$ endings mark the unexpressed subjects of person grouping G3: 3rd person only. This amounts to the exclusion of 1st- and 2nd-person subjects. Finally, the KP4 ending marks the unexpressed subjects of person grouping $\mathrm{G}_{4}$, 2nd or 3rd person alone. As explained above, this person grouping is characterizable as exclusion of the 1st person.

\subsection{Korean non-past endings in wh-questions}

We finally examine the Korean wh-question of non-past time reference, as exemplified in (8). It is also a conversation between A and B similar to (6) above. In example (8), however, the second utterance of B's is supposed to be concluded with non-past endings, as implied by its translation: "When will (I/she/we) meet Chulsu next time?”

(8) (A, B, and C are Chulsu's friends)

A: C-ga jumal-e Cheolsu-reul mana-ss-dae. C-NOM weekend-at Chulsu-ACC meet-PST-EVD '(I hear) $\mathrm{C}$ met Chulsu last weekend.'

B: Eo, geurae. Daeum-e eonje jjum manna-na/lgga? (class KN1) oh so last:time-at when about meet-SE 'Oh, really? When will (I/she/we) meet Chulsu next time?'

Here as well four classes of sentence endings can take place in the sentence-final position of B's second utterance, as shown in table 4 . We use a label ' $\mathrm{KN}$ ' to refer to the four classes of Korean non-past endings. When the sentence endings in class $\mathrm{KN}_{1}$ (-na and -lgga) are used, the unexpressed subject of the verb manna, 'meet,' must be 'I,' 'she,' or exclusive 'we,' as indicated in the translation of B's utterance. This corresponds to person grouping $\mathrm{G} 1$, represented in single-underlined letters. 
Table 4: Person reference in Korean non-past (KN) sentence endings

\begin{tabular}{|c|c|}
\hline 1 & $-n a,-\lg g a$ (class KN1); - ji (class KN2) \\
\hline 2 & -ji (class KN2); - $a,-n e u n g e o y a,-n e u n g e o j i ~(c l a s s ~ K N 4)$ \\
\hline 3 & $\begin{array}{l}- \text { na, -lgga (class KN1); -ji (class KN2); -neungeolgga (class } \\
\mathbf{K N 3}) ;-a,- \text { neungeoya, -neungeoji (class KN4) }\end{array}$ \\
\hline $1+2$ & (class KN1); (class KN2); (class KN4) \\
\hline $1+3$ & (class KN1); (class KN2) \\
\hline $1+2+3$ & (class KN1); (class KN2); (class KN4) \\
\hline $2+3$ & (class KN2); (class KN4) \\
\hline
\end{tabular}

Simultaneously, when the KN2 ending ( $-j i)$ is used, the unexpressed subject is understood to be any of 'I,' 'you,' 'she,' or 'we,' which conforms with person grouping G2, represented in double-underlined letters. In contrast, when the $\mathrm{KN} 3$ ending (-neungeolgga) appears in the sentence, the unexpressed subject is understood to be 'she' only. This is identical to person grouping $\mathrm{G}_{3}$, represented in wavy-underlined letters. On the other hand, when the $\mathrm{KN} 4$ endings (-a, -neungeoya, and -neungeoji) occur in the sentence, the unexpressed subject will be either 'you' or 'you \& she' or inclusive 'we.'

The person distributions of the unexpressed subjects observed with the four classes of non-past sentence endings in Korean wh-question (8) can be summarized as shown in (9). The $\mathrm{KN1}$ endings mark the unexpressed subjects of person grouping G1: 'I/we/she.' The KN2 ending marks the unexpressed subjects of person grouping G2: any of the persons. The $\mathrm{KN}_{3}$ ending marks the unexpressed subjects of person grouping $\mathrm{G}_{3}$ : 3rd person only. On the other hand, the KN4 endings mark 'you' or 'you \& she' or inclusive 'we.' This person grouping is not found with any other classes of endings in Korean, let alone in Japanese. We will henceforth refer to it as $\mathrm{G} 7$.

(9) The endings in class KN1 mark $1(+2)(+3) / 3$-person subjects.

$$
\text { [I/we/she'] (Grouping 1) }
$$

The ending in class KN2 marks $1(+2)(+3) / 2(+3) / 3$-person subjects.

[no exclusion] (Grouping 2)

The ending in class KN3 marks 3-person subjects.

[exclusion of 'you/I'] (Grouping 3)

The endings in class $\mathrm{KN}_{4}$ mark $2(+1)(+3) / 3$-person subjects.

['you/she/you \& I'] (Grouping 7)

\section{Pragmatic person grouping and person marking}

We will here account for the person marking of Japanese and Korean sentence endings in $w h$-questions with respect to pragmatic grouping of persons. 


\subsection{Person grouping in $w h$-questions}

Now we present an overview of person groupings found with the sentence endings of Japanese and Korean wh-questions. We confirmed above that there are seven types of person groupings for the unexpressed verb subjects of those sentences such as G1 through G7, as summarized in (10). Let's here consider what those person groupings reveal about the speech event conception or conversational setting.

(10) Grouping 1: 1(+2)(+3)/3-person subjects. ['I/we/she']

Grouping 2: $1(+2)(+3) / 2(+3) / 3$-person subjects. [no exclusion]

Grouping 3: 3-person subjects. [exclusion of 'you/I']

Grouping 4: 2 $(+3) / 3$-person

Grouping 5: 1(+3)-person subjects. ['I' or exclusive 'we']

Grouping 6: $1+2(+3)$-person subjects. [inclusive 'we']

Grouping 7: $2(+1)(+3) / 3$-person subjects. ['you/she/you \& I']

Traditionally, major linguistic descriptions have assumed a person/number distinction such as the one depicted in Figure 1. However, Cysouw (2000) cast doubt on such a traditional view of person distinction and proposed an eight-person distinction like the one described in Figure 2. We will follow his proposal and attempt an analysis of the seven types of person groupings found in the Japanese and Korean sentence endings of wh-questions.

\begin{tabular}{|l|l|}
\hline 1 & $\begin{array}{l}1+1 ; \\
1+2 ; \\
1+2+3 ; \\
1+3\end{array}$ \\
\hline 2 & $\begin{array}{l}2+2 ; \\
2+3\end{array}$ \\
\hline 3 & $3+3$ \\
\hline
\end{tabular}

Figure 1: traditional distinction

\begin{tabular}{|l|l|}
\hline 1 & $1+2$ \\
\cline { 2 - 2 } & $1+2+3$ \\
\cline { 2 - 2 } & $1+3$ \\
\hline 2 & $2+3$ \\
\hline 3 & $3+3$ \\
\hline
\end{tabular}

Figure 2: 8-person distinction

The seven types of person groupings in (10) can be mapped on Cysouw's (2000) eight-person distinction, as in Figure 3. Each grouping is represented in the respective line patters: Grouping 1 in single-underlined, Grouping 2 in double-underlined, Grouping 3 in wavy-underlined, Grouping 4 in broken-underlined, and Groupings 5 through 7 in shaded. 


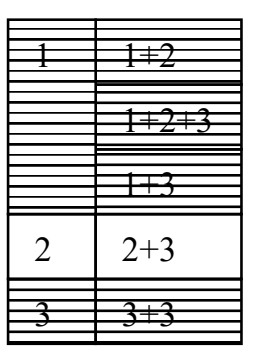

G1

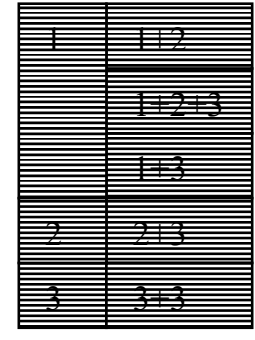

G2

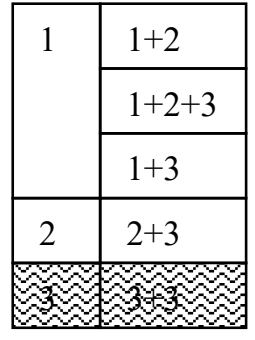

G3

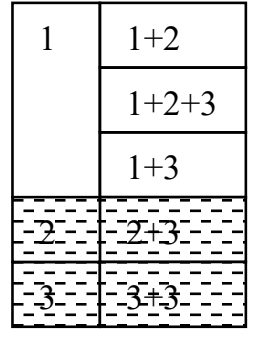

G4

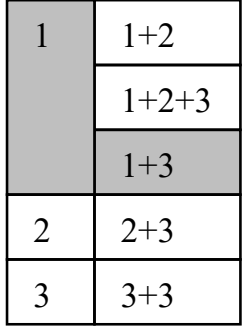

G5

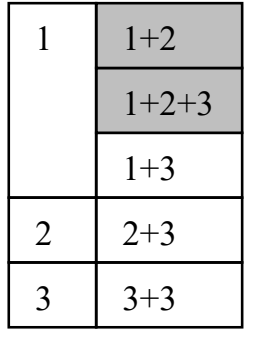

G6

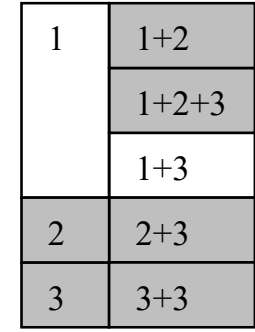

G7

Figure 3: person groupings of $\mathrm{G} 1$ through $\mathrm{G} 7$

Here we can see G1, G2, G3, and G4 are grounded on three-person (1/2/3) distinction with no regard to number. In contrast, G5, G6, and G7 are based on the inclusive/exclusive distinction of 1st person. G7 can be viewed as the union of G4 and G6 and corresponds to the complementary set of $\mathrm{G}_{5}$.

\subsection{Pragmatic grouping of topic persons}

The person groupings of G1 through $\mathrm{G}_{4}$ can be located in the speech-event conception of conversation, which can be diagramed as in Figure 4. G1 mainly covers a "speaker group," namely inclusive and exclusive 'we,' and secondarily someone other than the addressee, as in (a). In contrast, G2 can be located in the speech-event conception, as in (b). It does not exclude any person from the unexpressed subjects. In clear contrast, G3 confines the unexpressed subject to someone other than the speech-event participants, as in (c). Similarly, G4 also narrows the unexpressed subject down to someone or some group excluding the speaker, as in (d). This specification or narrowing down of unexpressed verb subjects can be viewed as reflections of pragmatically motivated groupings of the participants involved in speech event conceptions. We can see G1 through G4 as the groupings of topic persons that occur most frequently in Japanese and Korean conversations. 
(a)

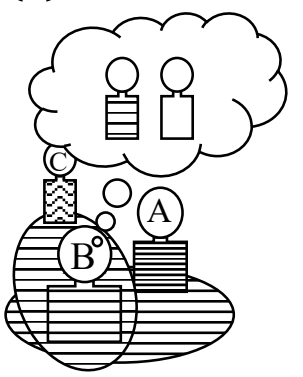

(b)

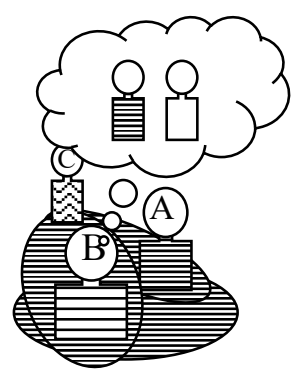

(c)

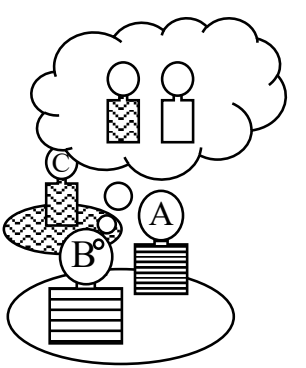

(d)

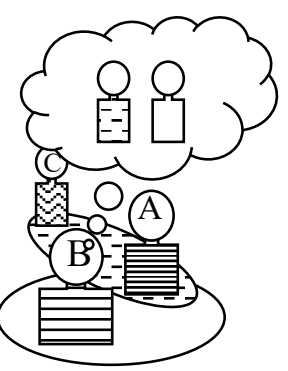

Figure 4: speech-event conceptions in person grouping G1 through G4

With the G1 marking, the speaker conveys, "I am asking you about us, inclusive or exclusive." With the G2 marking, the speaker can ask about any of you, me, us, and someone else." With the G3 marking, the speaker can communicate, "I am asking you not about us but someone else." With the G4 marking, the speaker can inform, "I am asking you not about me but you, him, or her."

Likewise, we can also see $\mathrm{G}_{5}$ through $\mathrm{G} 7$ as the pragmatic groupings of topic persons that occur frequently in Japanese and Korean conversations. They can be diagramed as in Figure 5. With the G5 marking, the speaker indicates, "I am asking you not about you but exclusive us, as in (a). With the G6 marking, the speaker can imply, I am asking you about inclusive us, as in (b). With the G7 marking, the speaker can suggest, "I am asking you about you or inclusive us, as in (c).

(a)

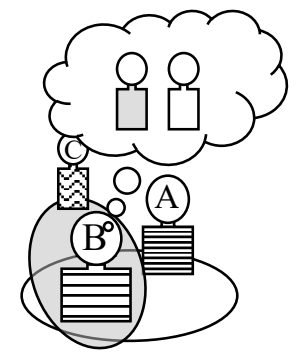

(b)

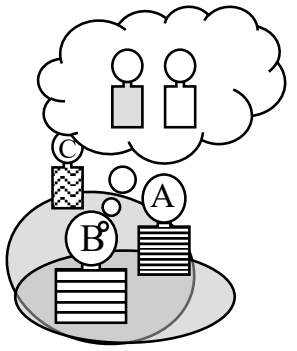

(c)

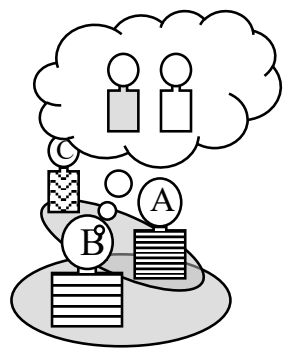

Figure 5: speech-event conceptions in person grouping G5 through G7

In conversation, we are accustomed to talking and asking about ourselves (G1/G5), an addressee (G7), or someone else (G3). In the event-participant reference, the speaker often stands alone ('I' in opposition to plural 'you') as seen in $\mathrm{G}_{4} / \mathrm{G}_{7}$ but is sometimes coupled with the addressee (a type of inclusive 'we') as in G1/G6 or with someone else in the discourse (exclusive 'we' in opposition to singular 'you') as in G5. Sometimes all the people are grouped together (another type of 'we,' 'everyone,' or 'none') as in G2.

These coupling and grouping of topic persons can be conventionalized and form pragmatically motivated categories, as may be the case with G1 
through G7. Comparable groupings can be found in other languages of the world, reported in Cysouw (2000) and Siewierska (2004). Such pragmatic person groupings or their motivated categories can further come to be matched up with frequently concurring sentence endings, which can thereby develop into markers of such person group categories. In Korean and Japanese, we can see the sentence endings of wh-questions as developing into such morphemes.

\section{Conclusion}

Korean and Japanese have a rich variety of sentence endings in whquestions as well as other sentence types. At face value they could be seen as complex forms with successive morphemes, each contributing to the whole meaning. However, they can be better understood as more or less "prefabricated" (Barlow 2000) simplex forms that came to be matched up with, and thus to mark, pragmatic groupings of topic persons in whquestions, which correspond to the unexpressed verb subjects.

In each language, pragmatic groupings of topic entities will likely be categorized into certain numbers of conceptual groupings frequently talked or asked about, which can manifest as morphemes that evoke or mark the subject. Such morphemes may be grammaticalized as verb endings (as in European languages) or sentence endings (as in Tibetan) of most sentence types. In Japanese and Korean, we can see the sentence endings of $w h$-questions as developing into such morphemes.

This study demonstrated that the Japanese and Korean sentence endings can be described as marking the unexpressed subject in whquestions. Interestingly, a comparable unexpressed-subject marking can be detected in yes/no-questions as well. However, the person grouping that each class of endings marks seems more or less different from whquestions. Some endings (e.g., JP1) reverse the 1st and 2nd-person subjects in wh- and yes/no-questions, while other endings (e.g., JN1) are per se difficult to use in yes/no-questions. For the time being, the sentence endings in yes/no-questions may not have progressed as much as those in wh-questions. Or they may comprise different types of person grouping from the types observed in $w h$-questions. We leave it to future research to investigate whether the Japanese and Korean sentence endings in yes/noquestions serve to mark the unexpressed subject and, if they do, how they function.

\section{References}

Barlow, M. 2000. Usage, blends and grammar. Barlow, Michael. \& S. Kemmer (eds.), Usage Based Models of Language. Stanford: CSLI, 315-345.

Cysouw, M. A. 2000. The Paradigmatic Structure of Person Marking. Ph.D dissertation, Catholic University of Nijmegen.

Kim, T. 2001. Gugeo Jonggyeoleomi eui Munbeob [A grammar of sentence endings in Korean]. Seoul: Kookhak. 
Koguma, T., Izutsu, K. 2017. Anchoring Speaker: A Conceptual Account of a Copula Distinction in Tibetan with Related Phenomena in Japanese, English \& Mongolian. Ningen Bunka 42: 2-7.

Nitta, Y. 1999. Nihongo no Modaritii to Ninshoo [Modality and person in Japanese], 2nd ed. Tokyo: Hituzi.

Shibatani, M. 1990. The Languages of Japan. Cambridge: Cambridge University Press.

Siewierska, A. 2004. Person. Cambridge: Cambridge University Press.

Sohn, H. M. 1999. The Korean Language. Cambridge: Cambridge University Press.

Sun, J. T. S. 1993. Evidentials in Amdo Tibetan. The Bulletin of the Institute of History and Philology 63: 945-1001.

Tournadre, N. 2008. Arguments against the concept of 'conjunct'/'disjunct' in Tibetan. Huber, B., M. Volkart, \& P. Widmer (eds.), Chomolangma, Demawend und Kabek: Festschrift für Ronald Bielmeier zu seinem 65. Geburrtstag. Halle: IITBS, 281-308. 